Artikel Riset

DOI : 10.33751/jf.v10i1.1728
Fitofarmaka Jurnal Ilmiah Farmasi

Vol.10, No.1, Juni $2020: 22-31$

p-ISSN : 2087-9164 e-ISSN : 2622-755X

\title{
PENGETAHUAN PENGGUNAAN OBAT ANTIBIOTIK \\ PADA MASYARAKAT YANG TINGGAL \\ DI KELURAHAN BABAKAN MADANG
}

\author{
Sara Nurmala*, Dewi Oktavia Gunawan \\ Program Studi Farmasi FMIPA Universitas Pakuan Bogor, \\ PO Box 452 Bogor 16143 \\ -E-mail: sara.nurmala@unpak.ac.id
}

\begin{abstract}
ABSTRAK
Penyakit infeksi masih menjadi salah satu masalah kesehatan masyarakat Indonesia yang sering terjadi terutama di Negara berkembang. Antibiotik merupakan obat yang digunakan untuk mengatasi penyakit infeksi. Tingginya insiden penyakit infeksi mengakibatkan tingginya penggunaan antibiotik. Penggunaan antibiotik yang tidak tepat akan menyebabkan timbulnya resistensi antibiotik. Saat ini banyak Masyarakat yang mendapatkan Anttibiotik tanpa resep Dokter dan tidak mendapatkan informasi yang cukup mengenai cara penggunaan Antibiotik yang tepat untuk pengobatan, sehingga menyebabkan tingginya kejadian resistensi Antibiotik. Tujuan penelitian ini untuk mengetahui tingkat pengetahuan penggunaan obat antibiotik pada Masyarakat yang tinggal di daerah suburban. Penelitian ini dilakukan dengan metode penelitian cross sectional study analytic dengan subjek 50 orang yang diambil secara simple random sampling di Puskesmas Babakan Madang Kabupaten Bogor. Analisis data yang digunakan yaitu analisis univariat dan bivariat dengan menggunakan chi square. Kuesioner yang digunakan telah diuji validitas dan reliabilitasnya. Kuesioner terdiri dari pertanyaan terkait dengan penggunaan obat antibiotik. Hasil uji statistik chi square menunjukkan terdapat hubungan yang bermakna antara pekerjaan dan jenis kelamin dengan pengetahuan penggunaan antibiotik $(\mathrm{p}<0,05)$ dan tidak terdapat hubungan yang bermakna antara usia dan Pendidikan dengan pengetahuan penggunaan antibiotik $(\mathrm{p}>0,05)$.
\end{abstract}

Kata kunci: Antibiotik, Pengetahuan Masyarakat, Penggunaan obat, Puskesmas.

\section{KNOWLEDGE THE USE OF ANTIBIOTIC DRUGS IN COMMUNITIES WHO LIVES IN BABAKAN MADANG}

\begin{abstract}
Infectious disease is still one of Indonesia's public health problems that often occurs, especially in developing countries. Antibiotics are drugs that are used to treat infectious diseases. The high incidence of infectious diseases results in high antibiotic use. Inappropriate use of antibiotics will cause antibiotic resistance. At present many people who get antibiotics without a doctor's prescription and do not get enough information about how to use antibiotics that are appropriate for treatment, causing a high incidence of antibiotic resistance. The purpose of this study was to determine the
\end{abstract}


level of knowledge of the use of antibiotic drugs in people who live in suburban areas. This research was conducted with a cross sectional analytic study method with 50 subjects taken by simple random sampling at the Babakan Madang Public Health Center in Bogor. Analysis of the data used is univariate and bivariate analysis using chi square. The questionnaire used was tested for validity and reliability. The questionnaire consisted of 10 questions related to the antibiotics used. Chi square statistical test results showed a significant relationship between work and knowledge of antibiotic use ( $p$ $<0.05)$. There was a significant relationship between sex with knowledge of antibiotic use $(\mathrm{p}<0.05)$, but there was no significant relationship between age with knowledge of antibiotic use ( $p>0.05)$ and there was no significant relationship between sex with knowledge of use antibiotics ( $p>0.05$ ).

Key words: Antibiotic Drugs, Community Knowledge, Drug Use, Suburban

\section{PENDAHULUAN}

Masalah resistensi antibiotik sangat komplek yang terjadi di Indonesia dan akan terus meningkat setiap tahunnya. Penyakit infeksi mencapai lebih dari 13 juta kematian per tahun di negara berkembang. (BPOM, 2011) Penyakit infeksi di Indonesia masih termasuk dalam sepuluh penyakit tertinggi, maka pada tahun 2050 kematian akibat resistensi antibiotik mencapai 10 juta pertahun dan menjadi penyebab kematian tertinggi diantara penyebab lain.

Penggunaan obat antibiotik di Indonesia yang cukup tinggi dan kurang tepat akan meningkatkan kejadian resistensi (Kementrian Kesehatan, 2011b). Tingkat resistensi bakteri di Indonesia terus meningkat, menurut Komite Pengendalian Resistensi Antimikroba dari tahun 2013, 2016, sampai 2019. Bakteri resisten itu semakin naik dari 40 persen, 60 persen, dan 60,4 persen pada tahun 2019. Peningkatan kejadian resistensi disebabkan karena adanya penggunaan antibiotik yang tidak terkendali. Bakteri resisten dapat terjadi karena kesalahan penggunaan antibiotik (Kementrian Kesehatan, 2011a).

Studi di Negara Eropa menunjukan bahwa resistensi terhadap obat antibiotik meningkat berbanding lurus dengan jumlah peningkatan konsumsinya, ini terjadi dikarenakan penggunaan antibiotik yang tidak rasional dan Pendidikan masyarakat yang tidak memadai (Ferri et al., 2017). Di Indonesia, penelitian pada RSUD Dr. Soetomo dan RSUD Dr.Kariadi yang dilakukan pada tahun 2008 menunjukkan bahwa sebesar 84\% pasien di rumah sakit mendapatkan resep antibiotik, sebesar 53\% diberikan sebagai terapi, sebesar $15 \%$ diberikan sebagai profilaksis, dan sebanyak $32 \%$ untuk indikasi yang tidak diketahui (Hadi et al., 2008).

Penggunaan antibiotik yang tepat dan bijak akan mengurangi tingkat resistensi. Pemahaman masyarakat yang menerima obat antibiotik sangat penting untuk keberhasilan terapi dan menghindari kejadian resistensi. Maka peranan Farmasis dalam hal ini menjadi sangat penting dalam hal memberikan informasi obat kepada pasien yang diberikan obat antibiotik. Penggunaan antibiotik yang disiplin sesuai aturan pakai akan meningkatkan kualitas kesehatan pasien, sebaliknya penggunaan tanpa aturan mengakibatkan keefektifan dari antibiotik akan berkurang. Ada hubungan yang signifikan antara pengetahuan dengan kepatuhan dalam penggunaan antibiotik dan hubungan yang signifikan antara keyakinan dan kepatuhan dalam penggunaan antibiotik. 
(Nuraini et al., 2018). Masyarakat yang memiliki tingkat pendidikan lebih tinggi akan lebih sedikit memutuskan penggunaan antibiotik, sedangkan mereka yang memiliki tingkat pendidikan lebih rendah cenderung memiliki pengetahuan antibiotik yang salah (Pan et al., 2016).

Penelitian ini dilakukan di Puskesmas Babakan Madang dimana pada puskesmas ini pemberian resep obat Antibiotik tidak diberikan oleh seorang Farmasis dan setiap hari rata-rata terdapat 10-20 pasien yang diresepkan Antibiotik. Sehingga pada penelitian ini peneliti ingin mengetahui pengetahuan pasien terkait penggunaan obat antibiotik di Puskesmas Babakan Madang kabupaten Bogor.

\section{METODE PENELITIAN}

Metode penelitian yang digunakan adalah cross sectional study. Penelitian dilaksanakan di Puskesmas Babakan Madang Kabupaten Bogor Kecamatan Babakan Madang. Pengambilan data primer dilaksanakan pada bulan Agustus Oktober 2019. Subjek pada penelitian ini adalah 50 pasien yang berobat di Puskesmas Babakan Madang dan tinggal di kelurahan Babakan Madang. Pengambilan sampel harus memenuhi kriteria inklusi dan eksklusi yang diambil secara simple random sampling.

Kriteria inklusi adalah bersedia menjadi responden, berdomisili di Perkampungan yang berada di kelurahan Babakan Madang, tidak memiliki penyakit degeneratif, penggunaan antibiotik lebih dari 3 kali, pernah menggunakan antibiotik tanpa resep dokter. Kriteria eksklusi adalah pasien tidak bersedia menjadi responden, tidak berdomisili di kelurahan babakan madang, memiliki penyakit degeneratif, baru pertama kali menggunakan antibiotik dan tidak pernah menggunakan antibiotik tanpa resep dokter.

Variabel terikat pada penelitian ini adalah pengetahuan penggunaan obat antibiotik. Variabel bebas pada penelitian ini adalah Jenis Kelamin, Usia, Pendidikan dan Pekerjaan.

Tahap penelitian terdiri atas dua tahap, tahap pertama dilakukan pengambilan data berupa angket yang menunjukan sejauh mana pengetahuan masyarakat terhadap antibiotik, cara penggunaan antibiotik, tujuan pemberian antibiotik, penggunaan antibiotik bersama obat lain, penggunaan obat antibiotik yang sering dilakukan dan cara membuang sisa antibiotik yang tidak habis. Kemudian setelah data sudah kita dapatkan tahap kedua adalah tahap mengkonfirmasi jawaban masyarakat, hal ini dilakukan agar masyarakat yang ternyata disimpulkan masih salah dalam penggunaan obat antibiotik dapat diberikan informasi yang benar agar kedepannya jika mereka mendapatkan resep antibiotik, mereka sudah mengerti dan paham sehingga menghindari dari resiko resistensi.

Kuesioner yang digunakan sudah divalidasi oleh peneliti. Pertanyaan pada kuesioner terdiri dari beberapa pertanyaan meliputi Penggunaan pentingnya melihat tanggal kadaluarsa obat tersebut, aturan pakai obat antibiotik misalnya diminum dua kali sehari artinya obat diminum setiap 12 jam, dan pentingnya menghabiskan obat antibiotic.

\section{ANALISIS DATA}

Analisis data yang digunakan yaitu analisis univariat dan bivariat dengan menggunakan chi square. 


\section{HASIL DAN PEMBAHASAN}

Jumlah subjek yang memenuhi kriteria inklusi dan ekslusi pada penelitian ini berjumlah 50 responden.

\section{Analisis Univariat}

1. Pengetahuan

penggunaan

antibiotik dengan resep dokter

bahwa persentase pengetahuan penggunaan antibiotik dengan resep dokter yaitu yang sudah mengetahui bahwa mendapatkan antibiotik harus dengan resep dokter mencapai 19 responden (38\%) dan responden yang belum mengetahui bahwa antibiotik harus didapatkan dengan resep dokter 31 responden $(62 \%)$.

Tabel 1. Distribusi Frekuensi Pengetahuan Penggunaan Antibiotik dengan Resep Dokter

\begin{tabular}{lcc}
\hline $\begin{array}{l}\text { Pengetahuan penggunaan } \\
\text { antibiotik dengan resep dokter }\end{array}$ & Frekuensi & $\%$ \\
\hline Mengetahui & 19 & $38 \%$ \\
Tidak Mengetahui & 31 & $62 \%$ \\
Total & 50 & $100 \%$ \\
\hline
\end{tabular}

2. Sikap masyarakat terhadap pengetahuan penggunaan antibiotik dengan resep dokter Berdasarkan Tabel 2 diketahui bahwa persentase sikap masyarakat yang setuju terhadap penggunaan antibiotik harus dengan resep dokter mencapai 46 responden $(92 \%)$ dan responden yang tidak setuju ada 4 responden $(8 \%)$.

Tabel 2. Distribusi Sikap Masyarakat Terhadap Pengetahuan Penggunaan Antibiotik dengan Resep Dokter

\begin{tabular}{lcc}
\hline $\begin{array}{l}\text { Sikap masyarakat terhadap } \\
\text { pengetahuan penggunaan antibiotik } \\
\text { dengan resep dokter }\end{array}$ & Frekuensi & $\%$ \\
\hline Setuju & 46 & $92 \%$ \\
Tidak Setuju & 4 & $8 \%$ \\
Total & 50 & $100 \%$ \\
\hline
\end{tabular}

\section{Analisis Bivariat}

\section{Hubungan antara Pengetahuan penggunaan obat antibiotik dengan jenis kelamin \\ Berdasarkan Tabel 3 dapat dilihat} bahwa persentase responden pria dan wanita yang sangat setuju pentingnya melihat tanggal kadaluarsa obat sebelum membeli obat adalah $20 \%$ dan $40 \%$.
Persentase responden yang setuju mengenai aturan pakai obat yang benar adalah pria $12 \%$ dan wanita $422 \%$. Hasil uji statistik menunjukkan bahwa terdapat hubungan yang bermakna antara jenis kelamin dengan pengetahuan penggunaan obat antibiotik yang benar $(\mathrm{p}<0,05)$ dan tidak terdapat hubungan yang bermakna antara jenis kelamin dengan 
kepatuhan responden dalam meminum obat dengan nilai $\mathrm{p}>0,05$.

Tabel 3. Hubungan Antara Pengetahuan Obat Antibiotik dengan Jenis Kelamin

\begin{tabular}{|c|c|c|c|c|}
\hline \multirow{2}{*}{\begin{tabular}{lr}
\multicolumn{2}{l}{ Pentingnya } \\
melihat tanggal \\
kadaluarsa & ketika \\
membeli & Obat \\
Antibiotik &
\end{tabular}} & \multicolumn{3}{|c|}{ Frekuensi } & \multirow[t]{2}{*}{$\mathrm{p}$ value } \\
\hline & $S$ & \multicolumn{2}{|r|}{ SS } & \\
\hline Pria & $8(16 \%)$ & \multicolumn{2}{|c|}{$10(20 \%)$} & \multirow{3}{*}{0,011} \\
\hline Wanita & \multicolumn{3}{|c|}{$20(40 \%)$} & \\
\hline Total & \multicolumn{3}{|c|}{$50(100 \%)$} & \\
\hline \multirow{2}{*}{$\begin{array}{l}\text { Aturan pakai obat } \\
2 \text { kali sehari } \\
\text { artinya diminum } \\
\text { setiap } 12 \text { jam. }\end{array}$} & \multicolumn{3}{|c|}{ Frekuensi } & \multirow{5}{*}{0,001} \\
\hline & $\mathrm{TS}$ & $\mathrm{S}$ & SS & \\
\hline \multirow{2}{*}{$\begin{array}{l}\text { Pria } \\
\text { Wanita }\end{array}$} & $10(20 \%)$ & $6(12 \%)$ & $2(4 \%)$ & \\
\hline & \multirow[t]{2}{*}{$2(4 \%)$} & $21(42 \%)$ & $9(18 \%)$ & \\
\hline Total & & $50(100 \%)$ & & \\
\hline \multirow{2}{*}{$\begin{array}{l}\text { Meminum Obat } \\
\text { antibiotik harus } \\
\text { sampai habis }\end{array}$} & \multicolumn{3}{|c|}{ Frekuensi } & \\
\hline & $\mathrm{TS}$ & $\mathrm{S}$ & SS & \\
\hline Pria & 0 & $11(22 \%)$ & $7(14 \%)$ & \multirow{3}{*}{0,609} \\
\hline Wanita & $1(2 \%)$ & $16(32 \%)$ & $15(30 \%)$ & \\
\hline Total & \multicolumn{3}{|c|}{$50(100 \%)$} & \\
\hline
\end{tabular}

2. Hubungan antara Pengetahuan penggunaan obat antibiotik dengan pekerjaan.

Berdasarkan Tabel 4 dapat dilihat bahwa persentase responden yang tidak bekerja lebih banyak yang menjawab sangat setuju pentingnya melihat tanggal kadaluarsa obat sebelum membeli obat adalah dan persentase responden yang tidak bekerja menjawab sangat setuju mengenai aturan pakai obat yang benar adalah 30\%. Hasil uji statistik menunjukkan bahwa tidak terdapat hubungan yang bermakna antara pekerjaan dengan pengetahuan penggunaan obat antibiotik yang benar ( $>0,05)$ dan terdapat hubungan yang bermakna antara pekerjaan dengan kepatuhan responden dalam meminum obat $(\mathrm{p}<0,05)$. 
Tabel 4. Hubungan Antara Pengetahuan Obat Antibiotik Dengan Pekerjaan

\begin{tabular}{|c|c|c|c|c|}
\hline \multirow{2}{*}{$\begin{array}{l}\text { Pentingnya melihat } \\
\text { tanggal kadaluarsa } \\
\text { ketika membeli Obat } \\
\text { Antibiotik }\end{array}$} & \multicolumn{3}{|c|}{ Frekuensi } & \multirow[t]{2}{*}{$\mathrm{p}$ value } \\
\hline & S & \multicolumn{2}{|c|}{ SS } & \\
\hline Tidak Bekerja & $3(6 \%)$ & \multicolumn{2}{|c|}{$20(40 \%)$} & \\
\hline Bekerja & $9(18 \%)$ & \multicolumn{2}{|c|}{$18(36 \%)$} & 0,094 \\
\hline Total & \multicolumn{3}{|c|}{$50(100 \%)$} & \\
\hline \multirow{2}{*}{$\begin{array}{l}\text { Aturan pakai obat } 2 \\
\text { kali sehari artinya } \\
\text { diminum setiap } 12 \\
\text { jam. }\end{array}$} & \multicolumn{3}{|c|}{ Frekuensi } & \\
\hline & $\mathrm{TS}$ & $\mathrm{S}$ & SS & \\
\hline Tidak Bekerja & $1(2 \%)$ & $15(30 \%)$ & $7(14 \%)$ & 0,053 \\
\hline Bekerja & $11(22 \%)$ & $12(24 \%)$ & $4(8 \%)$ & \\
\hline Total & & $50(100 \%)$ & & \\
\hline \multirow{2}{*}{$\begin{array}{l}\text { Meminum Obat } \\
\text { antibiotik harus } \\
\text { sampai habis }\end{array}$} & \multicolumn{3}{|c|}{ Frekuensi } & \\
\hline & $\mathrm{TS}$ & $\mathrm{S}$ & SS & \\
\hline Tidak Bekerja & $1(2 \%)$ & $8(16 \%)$ & $14(28 \%)$ & \\
\hline Bekerja & 0 & $19(38 \%)$ & $8(16 \%)$ & \\
\hline Total & & $50(100 \%)$ & & \\
\hline
\end{tabular}

3. Hubungan antara Pengetahuan obat antibiotik dengan usia.

Berdasarkan Tabel 5 dapat dilihat bahwa usia 20-30 mendominasi dengan persentase responden yang sangat setuju pentingnya melihat tanggal kadaluarsa obat sebelum membeli obat adalah $34 \%$. 
Tabel 5. Hubungan Antara Pengetahuan Obat Antibiotik dengan Usia

\begin{tabular}{|c|c|c|c|c|}
\hline \multirow{2}{*}{$\begin{array}{l}\text { Pentingnya } \\
\text { melihat tanggal } \\
\text { kadaluarsa ketika } \\
\text { membeli Obat } \\
\text { Antibiotik }\end{array}$} & \multicolumn{3}{|c|}{ Frekuensi } & \multirow{2}{*}{$\mathrm{p}$ value } \\
\hline & \multicolumn{2}{|l|}{$S$} & SS & \\
\hline $20-30$ tahun & \multicolumn{2}{|l|}{$3(6 \%)$} & $17(34 \%)$ & \multirow{5}{*}{0,572} \\
\hline 31-40 tahun & \multicolumn{2}{|l|}{$6(12 \%)$} & $13(26 \%)$ & \\
\hline 41-50 tahun & \multicolumn{2}{|l|}{$3(6 \%)$} & $7(14 \%)$ & \\
\hline$>50$ tahun & 0 & & $(22 \%)$ & \\
\hline Total & \multicolumn{3}{|c|}{$50(100 \%)$} & \\
\hline \multirow{2}{*}{$\begin{array}{l}\text { Aturan pakai obat } \\
2 \text { kali sehari } \\
\text { artinya diminum } \\
\text { setiap } 12 \text { jam. }\end{array}$} & \multicolumn{3}{|c|}{ Frekuensi } & \\
\hline & $\mathrm{TS}$ & $S$ & SS & \\
\hline 20-30 tahun & $4(8 \%)$ & $10(20 \%)$ & $6(12 \%)$ & \\
\hline 31-40 tahun & $6(12 \%)$ & $9(18 \%)$ & $4(8 \%)$ & \multirow{4}{*}{0,704} \\
\hline $41-50$ tahun & $2(4 \%)$ & $7(14 \%)$ & $1(2 \%)$ & \\
\hline$>50$ tahun & 0 & $1(2 \%)$ & 0 & \\
\hline Total & & $50(100 \%)$ & & \\
\hline \multirow{2}{*}{$\begin{array}{l}\text { Meminum Obat } \\
\text { antibiotik harus } \\
\text { sampai habis. }\end{array}$} & \multicolumn{3}{|c|}{ Frekuensi } & \\
\hline & $\mathrm{TS}$ & $S$ & SS & \\
\hline 20-30 tahun & $1(2 \%)$ & $11(22 \%)$ & $8(16 \%)$ & \\
\hline 31-40 tahun & 0 & $10(20 \%)$ & $9(18 \%)$ & \\
\hline 41-50 tahun & 0 & $5(10 \%)$ & $5(10 \%)$ & \\
\hline$>50$ tahun & 0 & $1(2 \%)$ & 0 & \\
\hline Total & & $50(100$ & & \\
\hline
\end{tabular}

Keterangan: TS (Tidak Setuju), S (Setuju), SS (Sangat Setuju)

Persentase responden yang setuju mengenai aturan pakai obat yang benar adalah $20 \%$ dan terdapat $22 \%$ responden yang setuju dengan cara meminum obat antibiotik dihabiskan. Hasil uji statistik menunjukkan bahwa tidak terdapat hubungan yang bermakna antara usia dengan pengetahuan penggunaan obat antibiotik yang benar $(\mathrm{p}>0,05)$. 
4. Hubungan antara Pengetahuan obat antibiotik dengan pendidikan

Berdasarkan Tabel 6 dapat dilihat bahwa Pendidikan tamatan SLTA mendominasi dengan persentase responden yang sangat setuju pentingnya melihat tanggal kadaluarsa obat sebelum membeli obat adalah $40 \%$ dan persentase responden yang setuju mengenai aturan pakai obat yang benar adalah $30 \%$ dan terdapat $36 \%$ responden yang setuju dengan cara meminum obat antibiotik dihabiskan. Hasil uji statistik menunjukkan bahwa tidak terdapat hubungan yang bermakna antara usia dengan pengetahuan penggunaan obat antibiotik yang benar $(p>0,05)$.

Tabel 6. Hubungan Antara Pengetahuan Obat Antibiotik dengan Pendidikan

\begin{tabular}{|c|c|c|c|c|}
\hline \multirow{2}{*}{$\begin{array}{l}\text { Pentingnya melihat } \\
\text { tanggal kadaluarsa } \\
\text { ketika membeli Obat } \\
\text { Antibiotik }\end{array}$} & \multicolumn{3}{|c|}{ Frekuensi } & \multirow{2}{*}{$\mathrm{p}$ value } \\
\hline & $\mathrm{S}$ & \multicolumn{2}{|r|}{ SS } & \\
\hline SLTA & $10(20 \%)$ & \multicolumn{2}{|c|}{$20(40 \%)$} & \multirow{3}{*}{0,160} \\
\hline Perguruan Tinggi & $2(4 \%)$ & & $18(36 \%)$ & \\
\hline Total & \multicolumn{3}{|c|}{$50(100 \%)$} & \\
\hline \multirow{2}{*}{$\begin{array}{l}\text { Aturan pakai obat } 2 \\
\text { kali sehari artinya } \\
\text { diminum setiap } 12 \\
\text { jam. }\end{array}$} & \multicolumn{3}{|c|}{ Frekuensi } & \multirow{2}{*}{$\mathrm{p}$ value } \\
\hline & TS & \multicolumn{2}{|r|}{$\mathrm{SS}$} & \\
\hline SLTA & \multirow{3}{*}{$\begin{array}{c}11(22 \%) \\
1(2 \%)\end{array}$} & $15(30 \%)$ & $4(8 \%)$ & \multirow{3}{*}{0,001} \\
\hline Perguruan Tinggi & & $12(24 \%)$ & $7(14 \%)$ & \\
\hline Total & & $50(100 \%)$ & & \\
\hline \multirow{2}{*}{$\begin{array}{l}\text { Meminum Obat } \\
\text { antibiotik harus } \\
\text { sampai habis }\end{array}$} & \multicolumn{3}{|c|}{ Frekuensi } & \multirow{2}{*}{$\mathrm{p}$ value } \\
\hline & TS & $\mathrm{S}$ & SS & \\
\hline SLTA & 0 & $18(36 \%)$ & $12(24 \%)$ & \multirow{3}{*}{0,786} \\
\hline Perguruan Tinggi & $1(2 \%)$ & $9(18 \%)$ & $10(20 \%)$ & \\
\hline Total & \multicolumn{3}{|c|}{$50(100 \%)$} & \\
\hline
\end{tabular}

\section{Hasil Validasi Kuesioner}

Kuesioner yang digunakan telah diuji validasi oleh peneliti dengan nilai korelasi yang signifikan yaitu pada level 0,01 .

\section{PEMBAHASAN}

Responden yang mengikuti penelitian ini berjumlah 50 orang yang merupakan pasien Puskesmas Babakan
Madang dan memenuhi faktor inklusi penelitian. Hasil uji Chi Square ditemukan $\mathrm{p}<0,05$. Dapat disimpulkan bahwa, terdapat hubungan yang bermakna antara jenis kelamin dengan pengetahuan penggunaan obat antibiotik. Perilaku kesadaran akan kesehatan tidak hanya dipengaruhi oleh sikap, tetapi juga oleh beberapa faktor individual lainnya, dari hasil penelitian ini dapat bahwa 
responden wanita persentasenya lebih tinggi dalam menjawab cara penggunaan obat antibiotik yang baik. Bila dilihat dari pengetahuan responden wanita yang baik, maka hal ini seperti teori yang dikemukan oleh Notoatmodjo, (2010) bahwa pengetahuan yang diperoleh subjek selanjutnya akan menimbulkan respon batin dalam bentuk sikap terhadap objek yang telah diketahuinya. seperti pengetahuan, kepercayaan, keyakinan dan nilai-nilai yang dianut oleh individu yang bersangkutan.

Hasil uji Chi Square juga ditemukan $\mathrm{p}<0,05$ terdapat hubungan yang bermakna antara pekerjaan dengan pengetahuan penggunaan obat antibiotik dalam hal ini kepatuhan dalam meminum obat antibiotik dengan p-value 0,033. Penelitian ini sesuai dengan penelitian Muthmainnah, (2010) yang menyatakan ada hubungan yang bermakna antara pekerjaan dengan tingkat pengetahuan seseorang (nilai $\mathrm{p}=0,041$ ).

\section{KESIMPULAN}

Berdasarkan hasil dan pembahasan dalam penelitian ini, maka dapat diambil kesimpulan bahwa: Tidak terdapat hubungan yang bermakna antara pengetahuan penggunaan obat antibiotik dengan usia dan pendidikan. Terdapat hubungan yang bermakna antara pengetahuan penggunaan obat antibiotik dengan jenis kelamin dan pekerjaan.

\section{UCAPAN TERIMA KASIH}

Ucapan Terima Kasih kami ucapkan kepada Ketua Program Studi Farmasi Universitas Pakuan yang telah membiayai penelitian ini.

\section{DAFTAR PUSTAKA}

Badan, P. 2011. Gunakan Antibiotik
Secara Rasional. Info POM, 12(2), $1-3$.

Ferri, M., Ranucci, E., \& Romagnoli, P. 2017. Antimicrobial Resistance: A Global Emerging Threat To Public Health Systems. Critical Reviews in Food Science and Nutrition, 57(13), 2857-2876.

Hadi, U., Duerink, D. O., Lestari, E. S., Nagelkerke, N. J., Werter, S., Keuter, M., Suwandojo, E., Rahardjo, E., van den Broek, P., \& Gyssens, I. C. 2008. Survey of antibiotic use of individuals visiting public healthcare facilities in Indonesia. International Journal of Infectious Diseases, 12(6), 622-629. https://doi.org/10.1016/j.ijid.2008.01 .002

Kementrian Kesehatan, R. I. 2011 a. Gunakan Antibiotik Secara Tepat Untuk Mencegah Kekebalan Kuman. In Buku Panduan Hari Kesehatan Sedunia.

Kementrian Kesehatan, R. I. 2011 b. Pedoman pelayan kefarmasian untuk terapi antibiotik.

Muthmainnah, F. 2010. Faktor-Faktor yang Berhubungan dengan Pengetahuan Ibu dalam Memberikan Makanan Pendamping Air Susu Ibu di Puskesmas Pamulang Tahun 2010. Universitas Negeri Islam Syarif Hidayatullah.

Notoatmodjo, S. 2010. Metodologi Penelitian Kesehatan. Rineka Cipta.

Nuraini, A., Yulia, R., Herawati, F., \& Setiasih. 2018. Hubungan Pengetahuan dan Keyakinan dengan Kepatuhan Menggunakan Antibiotik Pasien Dewasa. Jurnal Manajemen Dan Pelayanan Farmasi, 8(4), 165174.

Pan, D. S. T., Huang, J. H., Lee, M. H. M., Yu, Y., Chen, M. I.-C., Goh, E. H., Jiang, L., Chong, J. W. C., Leo, 
Y. S., Lee, T. H., Wong, C. S., Loh, V. W. K., Poh, A. Z., Tham, T. Y., Wong, W. M., \& Lim, F. S. 2016. Knowledge, attitudes and practices towards antibiotic use in upper respiratory tract infections among patients seeking primary health care in Singapore. BMC Family Practice, 17(1), 148. https://doi.org/10.1186/s12875-0160547-3 